\title{
EL TALANTE HUMANO-ESPIRITUAL DE TERESA DE JESÚS
}

DOI: https://doi.org/10.52039/seminarios.v61i214.171

FRANCISCA SELLÉS JUAN*

INTRODUCCIÓN

Voy a centrar este trabajo en la persona de Teresa de Jesús, ofreciendo unas breves pinceladas de los rasgos más significativos de esta mujer que se empeñó en vivir intensamente la amistad con un Dios cercano, al que experimentó como el verdadero Amigo. Me serviré de los textos que ella escribió a lo largo de su fecunda vida, porque pienso que Teresa puede ser un auténtico despertador y animadora del itinerario personal al que nos invita. Ciertamente, su vida y sus escritos, que son una manifestación de la propia vida, constituyen una propuesta de presente y futuro para la Iglesia y el mundo actual ${ }^{1}$.

«Nosotros amamos porque Él nos amó primero» (1 Jn 4, 19). Teresa es un ejemplo luminoso del mensaje que encierran estas palabras. Porque fue amada por el Amor, pudo desplegar su inmensa capacidad de amar y ser amada. Porque Dios la invitaba con libertad a centrar su vida en la Verdad, pudo actuar con libertad, en constante búsqueda de la verdad. Y porque fue cercada, buscada por Jesús, quien la invita a entrar en diálogo con Él, Teresa ofrece su testimonio para «engolosinar» a todos, sin excepción, para que puedan llegar a ser «amigos fuertes de Dios» (V 15, 5).

En primer lugar, Teresa, mujer unificada desde el «centro muy interior del alma» (7M 2, 3), es aquella que habiendo experimentado a Jesús en amistad, se dejó transformar, recrear por el Único capaz de armonizar todas las capacidades y ámbitos del ser humano. Por eso, no vemos en Teresa diferentes compartimentos o caras, no está la Teresa humana por un lado y la Teresa espiritual por otro, sino una mujer que, confiando plenamente en Dios y en quienes la iluminaban, recorrió un itinerario que la llevó a ser una persona unificada desde su interior.

Se puede considerar a Teresa una persona muy cercana a nosotros, como una compañera de camino, como amiga que se implica con quien a ella se acerca, y desea hablarle y escucharla. Por eso, se puede afirmar que su vida

* Religiosa, carmelita descalza en el convento de Puzol (Valencia).

1. Las citas de las obras de Santa Teresa están tomadas de las Obras Completas, Editorial de Espiritualidad, Madrid 2000. Las siglas utilizadas son: CV: Camino de Perfección, autógrafo de Valladolid; CC: Cuentas de conciencia; E: Exclamaciones; F: Fundaciones; M: Moradas; V: Libro de la Vida. 
constituye una guía que puede iluminar nuestro camino, porque la experiencia que encarnó es una llamada, una invitación a hacerla nuestra. La atracción que Teresa suscita, viene dada por la universalidad de su camino, no es para pocos escogidos sino que cualquier persona puede entablar amistad con Jesús y Teresa no hace sino mostrarnos que es posible hacerla realidad: «No es aceptador de personas; a todos ama; no tiene nadie excusa por ruin que sea, pues así lo hace conmigo trayéndome a tal estado» $(\mathrm{V} 27,12)$.

\section{TERESA, EL DINAMISMO DE LA AMISTAD}

Uno de los rasgos que sobresale con mayor fuerza en la persona de Teresa es su capacidad de entablar relaciones. Desde joven, Teresa se sabe poseedora de este don que le abre a la amistad y a la confianza con quienes están a su lado, confesará en el Libro de la Vida: «Vínose a entender que adonde yo estaba tenían seguras las espaldas, y en esto estaban con las que yo tenía amistad» $(V 6,3)$; «en esto me daba el Señor gracia, en dar contento adondequiera que estuviese, y así era muy querida» $(\vee 2,8)$.

Compartir lecturas de libros de caballerías con su madre, que le fomentó esta afición, lecturas de vidas de santos, juegos y aspiraciones de eternidad con su hermano Rodrigo; más tarde, confidencias y conversaciones con sus amigas y parientes, van configurando una persona con grandes dotes sociales.

Cuando se encuentre en el Monasterio de las Agustinas de Gracia (1531), adonde su padre la había llevado para apartarla de ciertas amistades, Teresa sintonizará con la monja que atendía a las jóvenes seglares, una mujer dotada de una madurez y profundidad extraordinarias. El diálogo con esta monja, María Briceño, irá paulatinamente transformando a la joven Teresa, que retomará un camino de vuelta a la oración y será el inicio de esa siembra de gracia que Dios irá derramando en ella, con el paso de los años.

Es el momento de hacer una opción en la vida, de decidir dónde proyectar la inmensa capacidad de amar y ser amada. Vive en una sociedad que relega a la mujer al hogar o al monasterio. No hay posibilidad de una vida auténticamente libre y autónoma, sin la supervisión o control por parte del varón. Y Teresa muestra, desde los inicios, inconformismo hacia ambos estilos de vida. Por un lado, ve los inconvenientes del matrimonio, y por otro, como ella misma confiesa, era «enemiguísima de ser monja» $(\mathrm{V} 2,8)$.

Lo que parecía tener muy claro desde la infancia era su deseo de eternidad, su deseo de agradar y contentar a los amigos y en el fondo, ser amiga de Dios, «porque no podía haber muerte más recia para mí que pensar si tenía ofendido a Dios» (V 34, 9). Esta intuición que Teresa albergaba en su fuero interno fue poco a poco creciendo y acrisolándose en el transcurrir del tiempo. Pero como ella misma dirá, su elección por la vida religiosa, fue más por temor que por amor: «más me parece me movía un temor servil que amor» $(\vee 3,6)$. 
De una manera pedagógica, como hace el Señor con cada uno de nosotros, acomodándose a nuestro ritmo, irá conduciendo a Teresa a una entrega cada vez mayor, hasta el punto de centrar su vida en el encuentro y la experiencia de un Dios encarnado en Jesús, «la Sagrada Humanidad». Y desde ese centro, llegar a todos y cada uno de los seres humanos, para dar voces y proclamar la grandeza del Amor que se nos regala en gratuidad.

La vida que llevaba Teresa en el Monasterio de la Encarnación de Ávila le llegó a hastiar las continuas visitas de personas que la requerían, pues con su simpatía y buen trato conseguía de ellas limosnas que constituían una fuente de ingresos para el Monasterio. Durante este tiempo, sostuvo Teresa una dura lucha interior, intentando concertar sus vanidades y amistades mundanas con la amistad a la que le invitaba, cual un susurro, el buen amador Jesús.

Es precisamente en ese clima de dispersión, donde nace el germen de la futura familia teresiana. Allí se le hace más presente a Teresa la centralidad del Amor en la persona de Jesús, porque en el fondo de su corazón lo ha vislumbrado, lo ha percibido, en diálogo con Él y con un pequeño grupito de hermanas, que, como ella, anhelan una vida evangélica, cimentada en la oración y la fraternidad: «Comenzóme mucho mayor amor y confianza de este Señor en viéndole, como con quien tenía conversación tan continua. Veía que, aunque era Dios, que era hombre, que no se espanta de las flaquezas de los hombres, que entiende nuestra miserable compostura. (...) Puedo tratar como con amigo, aunque es Señor, porque entiendo no es como los que acá tenemos por señores, que todo el señorío ponen en autoridades postizas» $(\vee 37,6)$.

Se irá produciendo un giro desde el temor al amor: «es cosa dañosa ir con miedo este camino» (CV 22, 3), amor que excluye todo temor: «En todo se puede tratar y hablar con Vos, como quisiéremos, perdido el primer espanto y temor de ver vuestra Majestad, con quedar mayor para no ofenderos; mas no por miedo del castigo, Señor mío, porque este no se tiene en nada en comparación de no perderos a Vos» $(\mathrm{V} 37,6)$.

Teresa se siente impulsada a compartir este tesoro que se le descubre en su corazón: «No nos imaginemos huecas en lo interior» (CV 28, 10); y desde esa certeza, alienta a sus hermanas, «que no sería poca merced que os hiciese el Señor despertar a alguna alma para este bien (amistad con Dios)» (CV 20, 6).

Su potencial relacional ha encontrado el cauce para vivir la autenticidad y radicalidad evangélica que ella ve en Jesús, quien la ha ido buscando, cercando, interpelando y a quien finalmente le ha rendido su corazón; de ahí que Teresa diga, con la fuerza que le da la experiencia vivida, estas palabras: «Aunque es verdad que son cosas que las da el Señor a quien quiere, si quisiésemos a su Majestad como Él nos quiere, a todas las daría. No está deseando otra cosa, sino tener a quien dar, que no por eso se disminuyen sus riquezas» $(6 \mathrm{M} 4,12)$.

Teresa es capaz de dialogar porque es capaz de escuchar. Quien está abierto al Otro y a los otros, en actitud de franca acogida, puede entablar diálogo, porque 
hay intercambio entre realidades diferentes a uno mismo; de otro modo, sería escucharse a uno mismo y en Teresa no encontramos monólogos, su palabra busca siempre interlocutor: Dios, las hermanas, los letrados... toda persona que se cruza en su camino. Y de ese diálogo brotará una palabra generadora de vida.

Es tal la importancia que para Teresa comportan las relaciones humanas, que formulará la definición de oración desde esa clave: «tratar de amistad, estando muchas veces tratando a solas con quien sabemos nos ama» $(\mathrm{V} 8,5)$.

Su capacidad de establecer vínculos se manifiesta en el extenso epistolario, que no es sino una pequeña muestra de la fecundidad de esta mujer, que se relacionó con personas procedentes de diversos campos y estamentos sociales y religiosos: mercaderes, venteros, nobles, religiosos, monjas, obispos, carteros, clérigos, hasta el propio rey Felipe II. En sus cartas se aprecia la calidad humana de Teresa, una mujer preocupada por los pequeños o grandes detalles que afectan al destinatario: salud, problemas económicos, espirituales. Reflejan todo tipo de sentimientos y sucesos que brotan al hilo del día a día: alegrías, preocupaciones, dudas, gozos, asuntos de compra, de venta, negocios, licencias...

Asimismo, el inmenso nudo de comunicaciones que se va estableciendo a medida que nacen nuevas fundaciones, constituye un núcleo de diálogo por el que van desfilando personas relacionadas con las mismas. Como acertadamente dice el P. Álvarez, uno de los mayores teresianistas de nuestro tiempo: «Su epistolario, resulta, así, un jirón de historia al natural, modesta y humilde, pero veraz; y una lección de vida humana y cristiana integral, sin adobos ni alambiques» ${ }^{2}$.

\section{TERESA, EN BÚSQUEDA DE LA VERDAD}

«La verdad debe buscarse de un modo adecuado a la dignidad de la persona humana y a su naturaleza social, es decir, mediante la investigación libre, con la ayuda del magisterio o enseñanza, de la comunicación y el diálogo, en los que unos exponen a los otros la verdad que han encontrado o piensan haber encontrado, para ayudarse mutuamente en la búsqueda de la verdad; una vez conocida la verdad, hay que adherirse a ella firmemente con el asentimiento personal ${ }^{3}$.

Estas palabras del Concilio Vaticano II, bien pueden reflejar el estilo de Teresa en cuanto buscadora de la verdad. Ella, que se dejó interpelar por la Verdad, invita a un camino de búsqueda, en constante discernimiento con quienes pueden ofrecer una palabra de luz y de verdad.

Busca el diálogo con los letrados, el compartir con los hermanos y las hermanas, en contraste con la Palabra, en los acontecimientos. Siempre en búsqueda, es la actitud de quien sabe que la verdad no queda encerrada en los límites de

2. Santa Teresa de Jesús, Cartas, Monte Carmelo, Burgos 1979, 8.

3. Concilio Ecuménico Vaticano II, Constituciones. Decretos. Declaraciones, BAC, Madrid 1993, 661. Declaración sobre la libertad religiosa Dignitatis humanae, 3. 
la suya propia, sino que adquiere su hondura y autenticidad desde el momento en que se acogen y comparten esos destellos de la Verdad, de los que somos portadores todas las personas.

Teresa se ve revelada a sí misma a medida que va dejándose iluminar por Jesús, por la Presencia que la habita; ve su verdad a la luz de la Verdad. Ya de niña decía que le quedó impreso el camino de la verdad en sus entrañas y ciertamente fue una mujer que jamás pactó con la mentira ni la doblez, aunque en sus primeros tiempos vivía una especie de "concierto a dos manos», o sea, quería armonizar su interior con su vida exterior que «tenía buenas apariencias» $(\vee 7,1)$.

Recorrió un proceso de búsqueda y encuentro, camino que estuvo jalonado por desvíos y distracciones pero que fructificará en un profundo y lúcido conocimiento de sí y de Dios: "Quedome una verdad de esta divina Verdad que se me representó, sin saber cómo ni qué, esculpida, que me hace tener un nuevo acatamiento a Dios, porque da noticia de su Majestad y poder, de una manera que no se puede decir: sé entender que es una gran cosa. Quedóme muy gran gana de no hablar sino cosas muy verdaderas, que vayan adelante de lo que acá se trata en el mundo, y así comencé a tener pena de vivir en él. Dejóme con gran ternura y regalo y humildad; paréceme que, sin entender cómo, me dio el Señor aquí mucho; no me quedó ninguna sospecha de que era ilusión. No vi nada, más entendí el gran bien que hay en no hacer caso de cosas que no sea para llegarnos más a Dios, y así entendí qué cosa es andar un alma en verdad delante de la misma Verdad. Esto que entendí es darme el Señor a entender que es la misma Verdad» (V 40, 3).

Porque quiere ser fiel al espíritu de la Iglesia y hacer verdad en su vida, ofrece su experiencia espiritual para ser discernida por aquellos que la pueden guiar y ayudar en su camino: «Tienen un no sé qué grandes letrados que, como Dios los tiene para luz de su Iglesia, cuando es una verdad, dásela para que se admita; $y$, si no son derramados sino siervos de Dios, nunca se espantan de sus grandezas, que tienen bien entendido que puede mucho más y más» $(5 M 1,7)$.

Jesuitas, a los que les profesaba gran admiración y respeto; entre ellos, san Francisco de Borja, que le infunde confianza en los primeros pasos de su proceso orante. Dominicos, como el P. García de Toledo, el P. Báñez, que fueron figuras relevantes de la Iglesia y que proporcionaron a la Santa la luz del Espíritu con la que discernir su experiencia.

Teresa tuvo especial interés en hacer llegar el Libro de la Vida a Juan de Ávila, considerado la mayor autoridad espiritual de su tiempo, para que diese su parecer. Es a través de su amiga $D .{ }^{a}$ Luisa de la Cerda, a la que apremia para que lleve su escrito al maestro Ávila: «En lo de aquel mi negocio (se refiere al Libro de la Vida), torno a suplicar a vuestra merced no se descuide, por las causas que le escribí, que me importa mucho» ${ }^{4}$. Y por fin recibe respuesta, aprobando su espíritu:

4. Carta a $D .^{a}$ Luisa de la Cerda, Ávila, 9 de junio de 1568, 5. 
«El maestro Ávila me escribe largo, y le contenta todo; solo dice que es menester declarar más unas cosas y mudar los vocablos de otras, que esto es fácil» ${ }^{5}$.

Sabe que el camino de la verdad es la posibilidad que ofrece el Señor a toda persona para ser cada vez más auténtica y configurarse con la imagen de Dios con que fuimos creados. Teresa anima a entrar en la dinámica del buscador de la Verdad, encarnada ésta en Jesús, a quien descubrió como el «libro verdadero adonde he visto las verdades. ¡Bendito sea tal libro, que deja imprimido lo que se ha de leer y hacer de manera que no se puede olvidar!» (V 26, 6).

Para que no quede en teorías o divagaciones sobre la verdad, Teresa acude al crisol de la convivencia diaria, donde se prueba la verdad de nuestra vida, porque existe el riesgo de acomodarse a las verdades particulares o incluso desvirtuarlas, jtan expertos somos, cuando nos conviene, en marear y esconder verdades!: "Yo os aviso no hagáis caso de estas virtudes, ni pensemos las conocemos sino de nombre, ni que nos las ha dado el Señor, hasta que veamos la prueba; porque acaecerá que, a una palabra que os digan a vuestro disgusto, vaya la paciencia por el suelo» (CV 38, 8). Como buena conocedora de la naturaleza humana, Teresa exclamará: «Somos amigos de contentos más que de cruz. ¡Pruébanos, Tú, Señor, que sabes las verdades para que nos conozcamos!» $(3 \mathrm{M} 1,9)$.

Es la consigna de Teresa, «andar en verdad» $(6 \mathrm{M} 10,7)$, que esa es la definición de humildad, porque para ella la autenticidad de la persona se refleja en esa capacidad de reconocer su verdad: «entendáis con verdad que no tenemos nada que no lo recibimos» (CV 38, 7), y por tanto, «mientras estamos en esta tierra, no hay cosa que más nos importe que la humildad» $(1 \mathrm{M} 2,9)$.

Bien entendida la humildad, que nada tiene que ver con la pusilanimidad o cobardía, sino que implica reconocer lo que somos y tenemos, recibido como don gratuito de la bondad de Dios: «No cure de unas humildades que hay, de que pienso tratar, que les parece humildad no entender que el Señor les va dando dones. Entendamos bien, bien, como ello es, que nos lo da Dios sin ningún merecimiento nuestro, y agradezcámoslo a su Majestad; porque, si no conocemos que recibimos, no despertamos a amar. Y es cosa muy cierta que, mientras más vemos estamos ricos, sobre conocer somos pobres, más aprovechamiento nos viene y aún más verdadera humildad. Lo demás es acobardar el ánimo a parecer que no es capaz de grandes bienes, si en comenzando el Señor a dárselos, comienza él a atemorizarse con miedo de vanagloria» $(\mathrm{V} 10,4)$.

\section{TERESA, MUJER DE PROPUESTAS}

Teresa, como buena buscadora de la Verdad, sabe que esta no se impone, se propone. Ha vivido la experiencia de verse buscada por la misma Verdad que es Jesús, con profundo respeto hacia ella; hasta que no le suplicó que le liberara

5. Carta a $D .^{a}$ Luisa de la Cerda, Ávila, 2 de noviembre de 1568, 4. 
de sus propias ataduras, Él, como buen amigo, supo esperar y respetar su ritmo, jalonado de idas y vueltas, luces y sombras.

En Teresa vemos claramente cómo fue obrando el Señor de forma progresiva; desde su juventud, cuando estaba atada a mil vanidades mundanas, fue paulatinamente dejándose liberar de las trabas que le impedían ser ella misma, por la fuerza transformadora de Jesús: «Cuando un alma comienza (por no la alborotar de verse tan pequeña para tener en sí cosa tan grande), no se da a conocer (el Señor) hasta que va ensanchándola poco a poco, conforme a lo que más ha menester para lo que ha de poner en ella. Por esto digo que trae consigo la libertad, pues tiene el poder de hacer grande este palacio todo» (CV 28, 12).

La libertad no es un logro conquistado por uno mismo, tampoco es el resultado de un ejercicio sistemático por lograr el objetivo deseado, aunque sí requiere empeño personal, «determinada determinación» en palabras de Teresa. Es un don de Dios que implica humildad y constancia para ir recorriendo el camino de liberación de los propios apegos y de todo aquello que constituye un freno para ir creciendo y madurando en el verdadero amor.

Teresa hablará claramente de que la libertad no tiene otro finalidad que la de amar, y libertad que no lleve a ese amor, «naciendo de raíz del amor de Dios» $(5 M 3,9)$, esclaviza y pierde su auténtica esencia. Jesús es el Hombre auténticamente libre porque hizo de su vida una entrega a la voluntad del Padre, con la entrega total a los hermanos. Teresa intuye que quienes desean alcanzar la verdadera libertad han de hacer de su vida una entrega semejante a la de Jesús, el que «nunca torno de sí» (CV 35, 3).

Entrega de amor al Amor que, lejos de esclavizar, libera, ensancha, transforma el corazón y capacita para amar. Este amor no imaginario, sino probado en la vida supone «forzar vuestra voluntad para que se haga en todo la de las hermanas, aunque perdáis de vuestro derecho, y olvidar vuestro bien por el suyo, aunque más contradicción os haga el natural; y procurar tomar trabajo por quitarle al prójimo, cuando se ofreciere. No penséis que no ha de costar algo y que os lo habéis de hallar hecho. Mirad lo que costó a nuestro Esposo el amor que nos tuvo, que, por librarnos de la muerte, la murió tan penosa como muerte de cruz» $(5 \mathrm{M} 3,12)$.

Esa libertad interior se manifiesta necesariamente en la vida, en las actitudes de quien sabe mirar a las personas sin prejuicios, lejos de las vanidades y las honras que catalogan y clasifican según el estamento o rango al que se pertenece.

Teresa luchó con fuerza para desenmascarar «la negra honra» que mata e impide la libertad y la verdad de las personas, por eso, exclamará: «Cualquiera persona que sienta en sí algún punto de honra, si quiere aprovechar, créame y dé tras este atamiento, que es una cadena que no hay lima que la quiebre, si no es Dios con oración y hacer mucho de nuestra parte. Paréceme que es una ligadura para este camino, que yo me espanto el daño que hace (...) que por poco que sea el punto de honra es como en el canto de órgano, que un punto o compás que se yerre disuena toda la música» (V 31, 20-21). 
Teresa sabe que una persona libre no se puede manipular, y por eso reclamará con energía la libertad para sus monjas, que no se dejen presionar ni acobardar por nadie, sino que sean mujeres maduras, que afronten con responsabilidad sus vidas: «Que nunca haya vicario que tenga mano de entrar y salir, ni confesor que tenga esta libertad, sino que estos sean para celar el recogimiento y honestidad de la casa y aprovechamiento interior y exterior, para decirlo al prelado cuando hubiere falta; mas no que sea él superior» (CV 5, 6). Bien podríamos encontrar en Teresa la exhortación que el autor de la Carta a los Efesios dirige a sus destinatarios, animándolos a construir el cuerpo de Cristo (Ef 4, 12-15), y a no dejarse arrastrar por cualquier viento de doctrina.

En una carta dirigida a una de sus primeras hijas, Ana de Jesús, le exhorta a actuar con libertad porque "va muy fuera del espíritu de descalzas ningún género de asimiento, aunque sea con superiora, ni medrarán en espíritu jamás. Libres quiere Dios a sus esposas, asidas a solo Él» ${ }^{6}$.

Esa es la propuesta de Teresa, «abrazándonos con solo el Criador y no se nos dando nada por todo lo criado» (CV 8, 1), ser personas libres para amar en gratuidad.

\section{TERESA, CAUCE DE HUMANIDAD}

«Bendito sea Dios que nos ha dejado ver una santa a quien todas podemos imitar, que come, duerme y habla como nosotras, y anda sin ceremonias» ${ }^{7}$.

Estas palabras, pronunciadas por la Abadesa de las Descalzas Reales de Madrid, son suficientemente elocuentes para hacernos una idea de la personalidad de Teresa de Jesús, una mujer que llama la atención por transparentar con sencillez su condición de ser humano.

Teresa se muestra natural, es espontánea, ayuda a desmitificar la santidad, que no es patrimonio de unos pocos sino que es una invitación universal dirigida a todos. Por eso, resulta una santa tan humana, tan cercana, porque entendió que quien posee impresa la imagen de Dios en su ser, es capaz de mostrarla en la realidad de la vida cotidiana, de manera semejante a Jesús, quien recorrió la vida «haciendo el bien» (Hch 10,38), con sencillez y sin ostentación de poder ni grandeza.

Como magnífica educadora que es, anima, aconseja, propone, estimula, sin coaccionar en ningún momento, sino presentando su propio testimonio con la única finalidad de que se vean las misericordias que el Señor ha derramado en ella.

Vivir con sencillez, con buenas dosis de alegría y sentido común, contando sus debilidades y dificultades con humor y simpatía, sin dramatizar, sino con sinceri-

6. Carta a Ana de Jesús, Burgos, 30 de mayo de 1582, 11.

7. Procesos de beatificación y canonización (I). Ana de Jesús (Lobera), en Biblioteca Mística Carmelitana 18, Monte Carmelo, Burgos 1934, 472. 
dad de corazón, reconociendo siempre Quién la conduce y anima en su recorrido vital, y poniéndose al servicio, «imitando al capitán del Amor, Jesús, nuestro bien» (CV 6, 9), son rasgos de humanidad que sintetizaré a continuación.

\section{Audacia}

Mucho se ha escrito sobre la audacia de Teresa. Sin duda que fue una mujer valerosa, fuerte, pero esta fuerza y audacia fueron siempre consideradas por ella como un don inmerecido, como un regalo de Dios. Ella se ve débil, temerosa, y es a partir del encuentro con la persona de Jesucristo cuando empieza a ir transformando sus temores en fortaleza interior, que la capacitará para emprender y afrontar todo tipo de situaciones y empresas: «Cuando Vos, Señor, queréis dar ánimo, ¡qué poco hacen todas las contradicciones!» $(F 3,4)$.

Y así, veremos a una mujer que fue capaz de hacer frente a los "espirituales» de su tiempo, de no temblar ante la Inquisición, de afrontar las dificultades de las nuevas fundaciones, de no temer a quienes quieren meter el miedo en las personas, por lanzarse a vivir la aventura de la oración. En fin, Teresa puede cantar con el profeta: «Mi fuerza y mi poder es el Señor, Él fue mi salvación» (Is 12, 2).

Sabe por experiencia propia que quien se abandona en las manos del Señor, con plena confianza, vence los miedos que le puedan paralizar: «Hasta ahora parecíame había menester a otros y tenía más confianza en ayudas del mundo; ahora entiendo claro ser todos unos palillos de romero seco y que asiéndose a ellos no hay seguridad, que en habiendo algún peso de contradicciones o murmuraciones, se quiebran. Y así tengo experiencia que el verdadero remedio para no caer es asirnos a la cruz y confiar en el que en ella se puso. Hállole amigo verdadero y hállome con esto con un señorío que me parece podría resistir a todo el mundo que fuese contra mí, con no me faltar Dios» (CC 3, 1).

Así pues, la valentía de Teresa viene dada por su amistad con Jesús, Amigo de «ánimas animosas», quien le infunde la fuerza para el camino.

\section{Alegría y buen humor}

La alegría es un don del Espíritu. Es la alegría profunda de saberse amado por Dios y no otra la que Teresa comunica, transmite y desea que gocen de ella todos. Es el gozo del Resucitado el que invita a vivir y compartir.

Teresa quería personas alegres, no encerradas en sus propios intereses, «encapotadas»; que vivan, con el gozo de saberse acompañados por Jesús aun en medio de las dificultades; incluso que prefieran ver loar al prójimo, antes que a uno mismo y sepan ocultar los defectos ajenos: «Mas esta alegría de que se entiendan las virtudes de las hermanas es gran cosa y, cuando viéremos alguna falta en alguna, sentirla como si fuera en nosotras y encubrirla» $(5 \mathrm{M} 3,11)$.

En otro orden de cosas, el sentido del humor le ayudó en gran medida a relativizar situaciones difíciles que jalonaron su itinerario. Su punto de ironía facilitaba 
el arte de vivir sin dramatismos, las dificultades inherentes a toda situación. Y así, en medio de una difícil fundación, como fue la de Burgos, poco antes de morir, escribe refiriéndose al arzobispo que le puso toda una serie de trabas: «Siempre decía que deseaba esta fundación más que nadie, y créolo, porque es tan buen cristiano, que no diría sino verdad. En las obras no se parecía, porque pedía cosas al parecer imposibles para lo que nosotras podíamos» ( $F$ 31, 31).

\section{Afabilidad}

Es otra de las grandes virtudes teresianas que ella inculcaba a sus hijas. Siempre procurar tratar a todos con suavidad, pues el trato afable y la cercanía que implica, es una manifestación del amor a los hermanos. Sus grandes dotes para la relación le enseñaron que sin cordialidad no se puede animar a las personas a emprender el camino de la oración, y por eso, a sus hijas, les insiste en que «mientras más santas, más conversables» y les anima a «ser afables y agradar y contentar a las personas que tratamos» (CV 41, 7).

\section{Flexibilidad}

Teresa fue una persona con gran sentido común y capacidad de distinguir lo esencial de lo accidental. Por tanto, no fue amiga de rigideces en ningún campo, buscaba el bien de la persona y sabía ver, por encima de la norma, el espíritu de la misma. No impone reglas ni ataduras que ahoguen, sino que conjuga suavidad y firmeza logrando el necesario equilibrio en el trato con las personas. «'Suave es su yugo' (Mt 11,30), y es gran negocio no traer el alma arrastrada, como dicen, sino llevarla con suavidad para su mayor aprovechamiento» $(\mathrm{V} 11,16)$.

Teresa insistirá en vivir el camino de la oración con discreción y flexibilidad: «No es menester andar tan encogidos ni apretados» (CV 41, 4), porque un alma encogida poco podrá madurar e ir creciendo como persona.

A uno de sus amigos y bienhechores, D. Teutonio de Braganza, arzobispo de Évora, le escribe una deliciosa carta en la que le anima y esponja el espíritu: «Procure vuestra señoría algunas veces, cuando se vea apretado, irse adonde vea cielo, y andarse paseando, que no se quitará la oración por eso, y es menester llevar esta nuestra flaqueza de arte que no se apriete el natural. Todo es buscar a Dios, pues por Él andamos a buscar medios, y es menester llevar el alma con suavidad ${ }^{8}$.

\section{Sencillez}

Verdad y llaneza es la conjunción teresiana por excelencia, es la clave para vivir sin espejismos, está íntimamente relacionada con la autenticidad. Supone desvestirse uno mismo y desvestir la realidad de ropajes que ocultan o propor-

8. Carta a D. Teutonio de Braganza, Segovia, 3 de julio de 1574, 4. 
cionan una visión parcial de la misma. Es la actitud de los limpios de corazón que son capaces de ver la esencia de las cosas y de las personas. Teresa no confunde sencillez con bobería, ella quiere personas con sentido común, con buen entendimiento. Desea ir a lo profundo, a lo auténtico, tanto de las personas como de los acontecimientos. "Yo le traté con toda llaneza mi alma, como tengo de costumbre» ( $F 30,1)$, dirá refiriéndose a uno de sus confesores, el doctor Velázquez, futuro obispo de Osma.

Íntimamente relacionada con esta virtud teresiana, está la pobreza, a la que Teresa define como «un bien que todos los bienes del mundo encierra en sí; es un señorío grande» (CV 2, 5); apunta no solo a la material, sino a esa sobriedad de espíritu que busca y encuentra su raíz en la esencialidad del amor a Jesús y a los hermanos.

En definitiva, Teresa apela a no aparentar lo que no somos sino reconocer la verdad de nuestro ser: «Delante de la Sabiduría infinita, créanme que vale más un poco de estudio de humildad y un acto de ella que toda la ciencia del mundo. Aquí no hay que argüir, sino que conocer lo que somos con llaneza, y con simpleza representarnos delante de Dios» $(\mathrm{V} 15,8)$.

\section{CONCLUSIÓN: TERESA, ASOMBRO Y AGRADECIMIENTO}

«Siempre he visto en mi Dios harto mayores y más crecidas muestras de amor de lo que yo he sabido pedir ni desear» $(E 5,2)$. Encontramos en todos los escritos de Teresa una cascada de expresiones de asombro y agradecimiento. No hay página en la que, de manera explícita o implícita, fluya una admiración honda por cuanto el Señor le va revelando, o un enorme agradecimiento por esa acción transformadora de Dios, no solo en ella sino en cuantos la rodean.

Se ve desbordada por el amor del Señor y esta experiencia, es la que la impulsa a hacer de su vida una existencia agradecida: «Pues la grandeza de Dios no tiene término, tampoco le tendrán sus obras. ¿Quién acabará de contar sus misericordias y grandezas?» $(7 \mathrm{M} 1,1)$; y en todo su periplo fundacional, constata: «Era tanto el gozo que tenía mi espíritu, que no me hartaba de dar gracias a nuestro Señor aquellos días, ni quisiera hacer otra cosa» ( $F$ 24, 2).

Sería difícil entender a Teresa sin esta condición que en ella brilla de manera especial; reconoce que los dones con que el Señor la ha regalado, proceden de la bondad y misericordia de Dios y ella es tan solo el cauce, el afluente por donde circula la gracia divina: «Bien sabéis Vos, mi Dios, que entre todas mis miserias nunca dejé de conocer vuestro gran poder y misericordia» $(E 4,2)$.

El asombro supone una mirada libre de prejuicios, implica dejarse sorprender por la Presencia que la habita; necesariamente esta experiencia le lleva a compartirla, proclamarla, «decir a voces tan grandes maravillas» $(V 38,21)$.

Teresa se percibe agraciada y se ve impulsada a reconocer con agradecimiento la misericordia y bondad de Dios que se le ha regalado a manos llenas: 
«Muchas veces he pensado espantada de la gran bondad de Dios, y regalándose mi alma de ver su gran magnificencia y misericordia. Sea bendito por todo, que he visto claro no dejar sin pagarme, aun en esta vida, ningún deseo bueno. Por ruines e imperfectas que fuesen mis obras, este Señor mío las iba mejorando y perfeccionando y dando valor, y los males y pecados luego los escondía; aun en los ojos de quien los ha visto, permite su Majestad se cieguen y los quita de su memoria. Dora las culpas; hace que resplandezca una virtud que el mismo Señor pone en mí, casi haciéndome fuerza para que la tenga» $(\mathrm{V} 4,10)$.

Concluyo con unas palabras de uno de sus consejeros, el P. Domingo Báñez, que, tras leer y valorar el Libro de la Vida, vislumbró en Teresa, cual si de un diamante se tratara, la luz del Espíritu Santo que Dios proyectó en ella, para que fuera un testigo elocuente de su Verdad, revelada en su Hijo Jesucristo: «su mucha experiencia de esta religiosa y su discreción y humildad en haber siempre buscado luz y letras en sus confesores la hacen acertar a decir cosas de oración, que a veces los muy letrados no aciertan así por la falta de experiencia (...). Tengo grande experiencia de su verdad, de su obediencia, penitencia, paciencia y caridad con los que la persiguen y otras virtudes que quien quiera que la tratare verá en ella. Y esto es lo que se puede apreciar como más cierta señal del verdadero amor de Dios, que las visiones y revelaciones (...). Ella no es engañadora, y así merece su claridad que todos la favorezcan en sus buenos propósitos y buenas obras». 